\title{
FUNGSI HUKUM ADAT DALAM PENGUATAN PERAN SEKAA TERUNA DI DESA ADAT KUTA UNTUK PERLINDUNGAN TRADISI MEDELOKAN PENGANTEN
}

\author{
Ni Komang Ratih Kumala Dewi \\ Fakultas Hukum Universitas Mahasaraswati Denpasar \\ Email : ratih_kumala2001@yahoo.co.id \\ I Wayan Agus Vijayantera \\ Fakultas Hukum Universitas Mahasaraswati Denpasar \\ Email : agus.vije@gmail.com \\ Putu Sekarwangi Saraswati \\ Fakultas Hukum Universitas Mahasaraswati Denpasar \\ Email : sekarwangisaraswati@gmail.com
}

\begin{abstract}
ABSTRAK
Sekaa teruna merupakan organisasi kepemudaan yang ada di Bali yang berada di masing-masing banjar pada desa adat di Bali. Organisasi sekaa teruna memiliki sebuah tradisi yang sejak dahulu dilaksanakan yakni tradisi medelokan penganten. Tradisi ini dilakukan organisasi sekaa teruna sebagai implementasi konsep Tri Hita Karana yakni menjaga hubungan baik antara sesama manusia (pawongan). Pola hidup masyarakat di Desa Adat Kuta yang semakin berkembang dalam sektor pariwisata serta gaya hidupnya akibat masuknya berbagai wisatawan ke daerah Kuta, dapat mengakibatkan indikasi berkurangnya peran organisasi sekaa teruna di Desa Adat Kuta dalam menjaga tradisi medelokan penganten, sehingga hal ini menarik untuk dilakukan penelitian. Penelitian ini dirancang dengan pendekatan kualitatif dengan menyoroti berbagai masalah terkait dengan tradisi medelokan penganten di Desa Adat Kuta, Kecamatan Kuta, Kabupaten Badung, serta penguatan peran sekaa teruna guna menjaga tradisi medelokan penganten. Berdasarkan hasil penelitian menunjukkan bahwa tradisi medelokan penganten merupakan tradisi bagi sekaa teruna yang sangat penting untuk dilestarikan. Kendala utama pelestarian tradisi medelokan penganten yakni kurangnya pemahaman pemuda dalam sekaa teruna terkait melaksanakan tradisi medelokan penganten. Peran sekaa teruna dirasakan perlu juga untuk dilakukan penguatan dengan hukum adat baik berupa awig-awig maupun pararem sehingga peran sekaa teruna semakin kuat untuk menjaga tradisi medelokan penganten.
\end{abstract}

Kata Kunci : Desa Adat, Sekaa Teruna, Medelokan penganten

\section{ABSTRACT}

Sekaa teruna is youth organization in Bali located in each banjar in traditional village in Bali. Sekaa teruna organization has a tradition that 
always been practiced by the medelokan penganten tradition. This tradition is done by sekaa teruna organization as implementation of Tri Hita Karana concept which maintains good relationship between human being (pawongan). Patterns of community life in Kuta Village growing in the tourism sector and lifestyle due to the entry of various destinations to Kuta area, can be relied upon to reduce the role of seka teruna organization in the Adat Kuta Village in maintaining the medelokan penganten tradition, so it is interesting to do research. This research designed with qualitative approach by highlighting various problems related the medelokan penganten tradition in Kuta village, and spirit of sekaa teruna role to keep the medelokan penganten tradition. Based on the results of research shows the medelokan penganten tradition for sekaa teruna is very important to be preserved. The main obstacle of preservation of medelokan penganten tradition is understanding of youth in sekaa teruna organization with the medelokan penganten tradition. The role of sekaa teruna also needs to be done to make improvements with customary law both awig and pararem own to meet the tradition of bride medelokan.

Keywords : Traditional Village, Sekaa Teruna, Medelokan penganten

\section{Pendahuluan}

Pulau Bali merupakan destinasi wisata yang paling diminati oleh wisatawan asing maupun wisatawan lokal. Terlepas dari keindahan alam yang disediakan di pulau ini, pulau Bali kaya akan kesenian dan budaya dan inilah yang merupakan daya tarik wisatawan untuk berkunjung ke Bali. Kesenian dan budaya merupakan identitas bagi manusia Bali sebagaimana yang dipaparkan oleh I Made Suastra (2009), bahwa yang menunjukkan seseorang beridentitas manusia Bali dapat berwujud bahasa (dalam bentuk bunyi) dan tradisi (dalam bentuk fisik). Kesenian dan kebudayaan yang ada di Bali terdapat beraneka ragam, sehingga mengundang wisatawan baik yang untuk sekedar menyaksikan atau melihat kesenian dan kebudayaan yang ada di Bali, maupun untuk mempelajari kesenian dan kebudayaan yang ada di Bali.

Berkenaan dengan tradisi, Bali memiliki berbagai macam ragam tradisi khas yang dimiliki setiap desa adat. Desa adat adalah kesatuan masyarakat hukum adat di daerah Bali, yang mempunyai satu kesatuan tradisi dan tata krama pergaulan hidup masyarakat umat Hindu, yang secara turun temurun dalam ikatan Kahyangan Tiga yang mempunyai wilayah tertentu, dan harta kekayaan tersendiri serta berhak mengurus rumah tangganya sendiri. Landasan dasar desa adat di Bali adalah konsep Tri Hita Karana (Acwin Dwijendra, 2003).

Desa adat Kuta sebagai daerah pariwisata yang paling banyak dikunjungi oleh wisatawan. Desa adat Kuta membawahi 13 banjar adat yaitu banjar Pandemas, banjar Temacun, banjar Segara, banjar Buni, banjar Pering, banjar Pelasa, 
banjar Mertajati, banjar Tegal, banjar Pemamoran, banjar Jabe Jero, banjar Tebasari, banjar Anyar, dan banjar Pengabetan. Setiap banjar tersebut memiliki sebuah organisasi kepemudaan yang disebut Sekaa teruna. Sekaa teruna sebagai organisasi masyarakat yang pengurus dan anggotanya adalah pemuda. Desa adat Kuta sebagai daerah pariwisata tentu memiliki berbagai budaya atau tradisi yang dijaga oleh masyarakatnya. Mengingat bahwa desa adat Kuta sebagai daerah Pariwisata, pergeseran budaya atau tradisi menjadi hal yang ditakutkan akibat perkembangan masyarakat serta pola hidup masyarakat Kuta. Oleh karena itu masyarakat terutama Sekaa teruna desa adat Kuta memiliki peran yang penting untuk menjaga budaya atau tradisi yang ada di desa adat Kuta.

Menurut Wahyu Isdhardino Satries, pemuda memiliki peran dan tanggung jawab dalam menjaga kesatuan dan persatuan bangsa serta sikap komitmen dan keberpihakan kepada masyarakat, oleh karena itu pemuda adalah elemen bangsa yang menyandang peran sebagai agen perubahan (agent of change), dan agen kontrol sosial (agent of social control) dalam masyarakat (Satries, 2009).

Peran permuda sebagai agen perubahan (agent of change), dan agen kontrol sosial (agent of social control) dalam masyarakat, sebagaimana dalam tulisan Aloysius Bram Widyanto, Belajar dari Ki Hajar Dewantoro, pemuda harus memiliki sifat Ing Ngarso
Sung Tulodo, Ing Madyo Mangun Karsoo dan Tut Wuri Handayani. Artinya pemuda harus berada di garda paling depan dalam melakukan perubahan sosial sebagai lokomotif perubahan. Di tengah pemuda harus bahu membahu bersama rakyat dalam mencapai kesejahteraan rakyat.Keadaan yang buruk ini harus segera diakhiri.Di belakang pemuda harus memberi semangat dan mendorong rakyat bahwa perubahan ke arah yang lebih baik atau yang dicita-citakan dapat tercapai jika mereka bersatu. Tantangan yang datang dari dalam maupun luar pasti dapat teratasi (Widyanto, 2010).

Setiap desa adat terutama pada desa adat Kuta memiliki sebuah tradisi yang berkenaan dengan perkawinan dan melibatkan peran sekaa teruna. Dalam kegiatan perkawinan anggota sekaa teruna, terdapat tradisi medelokan penganten yang dilakukan oleh sekaa teruna yang disebut tradisi medelokan penganten. Tradisi ini dilakukan oleh sekaa teruna sebagai implementasi dari konsep Tri Hita Karana yang bersangkutan dengan menjaga hubungan antara sesama manusia (pawongan). Konsep medelokan penganten sebagaimana dalam penelitian I Made Juniarta (2013), setiap anggota sekaa teruna yang kawin, beberapa hari sebelum upacara perkawinan akan datang menjenguk atau sering disebut medelokan kerumah mempelai.

Permasalahan atau isu yang ditemukan yakni tidak semua 
sekaa teruna di masing-masing banjar desa adat Kuta melaksanakan tradisi medelokan penganten ini. Hal ini bisa saja diakibatkan perkembangan pariwisata yang mengakibatkan pola kehidupan masyarakat berubah menjadi modern. Pola kehidupan masyaraka yang cenderung modern akan mengindikasikan menghilangnya pemahaman masyarakat terhadap adat dan tradisinya serta pelaksanaannya. Hal ini juga akan berpengaruh pada peran sekaa teruna dalam memahami dan melaksanakan tradisi medelokan penganten. Oleh karena itu perlu adanya penguatan peran sekaa teruna untuk melindungi tradisi medelokan penganten agar tradisi ini tidak menghilang atau punah. Berdasarkan hal tersebut maka adapun yang menjadi permasalahan yakni menyangkut pentingnya peran sekaa teruna desa adat Kuta dalam menjaga tradisi medelokan penganten serta upaya untuk penguatan peran sekaa teruna desa adat Kuta dalam perlindungan tradisi medelokan penganten.

\section{Metode Penelitian}

Penelitian ini dirancang dengan pendekatan kualitatif. Penelitian ini dilaksanakan di Desa Adat Kuta, Kelurahan Kuta, Kecamatan Kuta Kabupaten Badung Provinsi Bali. Lokasi penelitian ini di pilih karena Desa Adat Kuta memiliki potensi yang besar di bidang pariwisata. Perkembangan pariwisata di daerah tersebut mengakibatkan perkembangan pola hidup masyarakat menjadi modern sehingga dapat mengindikasikan terjadinya pergeseran tradisi. Untuk mendapatkan data yang diperlukan, subyek penelitian adalah sekaa teruna Desa Adat Kuta, Kelurahan Kuta, Kecamatan Kuta Kabupaten Badung Provinsi Bali. Teknik pelaksanaan penelitian dengan Teknik pengumpulan data dan Penyusunan strategi terhadap permasalahan permasalahan yang berkaitan dengan tradisi medelokan penganten Desa Adat Kuta.

\section{Pembahasan}

\section{Pengertian Sekaa teruna di Bali}

Di Bali telah berkembang suatu organisasi yang disebut dengan sekaa teruna. Salah satu simpul budaya lokal dalam unit desa pakraman yang menarik untuk ditelaah keberadaannya adalah Sekaa Teruna. Teruna dalam bahasa Bali yang berarti Pemuda menyiratkan bahwa organisasi ini bergerak dalam bidang sosial kepemudaan. Organisasi ini mampu menghimpun generasi muda yang memiliki karakter berbeda-beda dan dapat menjadi wadah yang baik dalam mengembangkan kreativitas para remaja untuk terus melestarikan budaya dan tradisi setempat. Sehingga keberadaan organisasi lokal ini harus menjadi warisan yang terus dan patut untuk dilestarikan (Herawati, 2017).

Sekaa Teruna adalah kumpulan atau wadah organisasi 
sosial pengembangan generasi muda yang tumbuh dan berkembang atas dasar kesadaran dan tanggung jawab sosial dari masyarakat terutama generasi muda di wilayah desa atau kelurahan yang bergerak dibidang kesejahteraan sosial (Made, 2015). Aktivitas sekaa teruna di seluruh Bali relatif sama, selain bersekolah atau kuliah (mengisi diri), aktivitas yang biasanya dilakukan (atas nama sekaa teruna) antara lain adalah membantu rekan (dalam satu banjar) pada saat perkawinan, menyelenggarakan bazzar di hari raya atau libur sekolah, mengikuti lomba layang-layang, melaksanakan ayah mewek (menjadi sukarelawan) pada saat upacara besar di desanya dan aktif dalam berbagai kegiatan bernuansa muda seperti beleganjur dan berbagai kegiatan kesenian Bali yang lainnya (Tobing, 2017) .

\section{Perlindungan Budaya Bali}

Pengertian perlindungan dalam bahasa inggris adalah protection.Sedangkan menurut Kamus Besar Bahasa Indonesia (KBBI) mengartikan perlindungan adalah tempat berlindung (Departeman Pendidikan Indonesia, 2008). Pemaknaan kata perlindungan secara kebahasaan tersebut memiliki kemiripan atau kesamaan unsur-unsur yaitu:

1. unsur tindakan melindungi

2. unsur pihak-pihak yang melindungi

3. unsur cara-cara melindungi Dengan demikian kata perlindungan mengandung makna yaitu, suatu tindakan perlindungan atau tindakan melindungi dari pihak-pihak tertentu yang ditujukan untuk pihak tertentu dengan menggunakan cara-cara tertentu.

Berbicara tentang budaya bali, tentunya kita semua tau bahwa Bali kaya akan kesenian dan budaya-budayanya yang masih sangat kental serta unik sehingga mampu mengundang orang-orang untuk ingin mengetahui lebih jauh maupun mempelajarinya, contohnya Kebudayaan Bali terkenal akan seni tari, seni pertujukan, dan seni ukirnya untuk itu banyak orang berpendapat bahwa orang Bali layak disebut sebagai seniman, sebab ada berbagai aktivitas seni yang dapat mereka lakukan lepas dari kesibukannya sebagai petani, pedagang, kuli, sopir, dan sebagainya mulai dari menari, bermain musik, melukis, memahat, menyanyi.

Bali juga terkenal dengan seni gamelan yang merupakan bentuk seni musik yang vital dalam berbagai acara tradisional masyarakat Bali.Setiap jenis musik disesuaikan dengan acaranya.Musik untuk piodalan (hari jadi) berbeda dengan musik pengiring acara metatah (mengasah gigi), demikian pula pernikahan, ngaben, melasti, dan sebagainya. Gamelan yang beraneka ragam pun disesuaikan dengan berbagai jenis tari yang ada di Bali. Selain itu Bali juga terkenal dengan pakaian adat Bali untuk perempuan yang masih remaja menggunakan sanggul 
gonjer, sedangkan perempuan atau wanita dewasa menggunakan sanggul tagel, kemudian menggunakan sesentang atau kemben songket, Kain wastra, Sabuk prada (stagen) untuk membelit pinggul dan dada, Selendang songket bahu ke bawah, Kain tapih atau sinjang, di sebelah dalam, Beragam ornamen perhiasan, Sering pula dikenakan kebaya, kain penutup dada, dan alas kaki sebagai pelengkap. Untuk pria menggunakan ikat kepala atau udeg lalu menggunakan selendang pengikat atau umpal, kain kampuh, kain wastra, keris, sabuk, kemeja atau jas, serta ornament yang digunakan untuk menghiasi penampilan sang pria.

Selain itu bali juga kental rumah adat Bali harus sesuai dengan aturan Asta Kosala Kosali ajaran terdapat pada kitab suci Weda yang mengatur soal tata letak sebuah bangunan yang hampir mirip dengan ilmu Feng Shui dalam ajaran Budaya China. Rumah adat Bali harus memenuhi aspek pawongan (manusia / penghuni rumah), pelemahan (lokasi / lingkungan) dan yang terahir parahyangan.Pada umumnya rumah Bali di penuhi dengan pernak-pernik hiasan, ukiran serta warna yang alami lalu patung-patung simbol ritual.

Adat budaya Bali dimana masyarakatnya terdiri dari masyarakat yang beragam namun semua itu tidak berpengaruh terhadap masyarakat lain yang tinggal di Bali namun tidak memeluk agama Hindu. Berikut beberapa upacara yang biasa di lakukan oleh masyarakat bali seperti upacara pernikahan, upacara potong gigi, dan upacara kematian. Dan tidak ketinggalan juga kerajinan khas Bali yang dibuat oleh masyarakat Bali, kerajinan tangan tersebut berupa membuat tas anyaman, ukiran bali berupa pajangan ataupun untuk pintu, kerajinan tangan yang terbuat dari perak maupun kaca, topeng kayu asal Bali, pernak pernik accessories Bali dan masih banyak lagi.

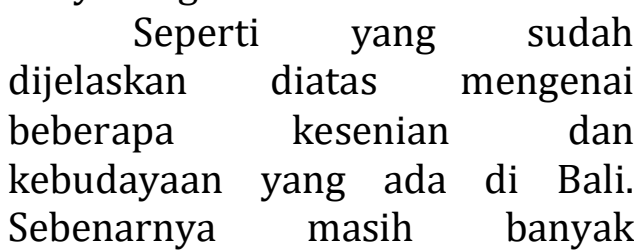
kesenian dan kebudayaan yang ada di daerah bali. Bali memiliki sebuatan pulau dewata, dan Bali pun merupakan pulau yang banyak dikunjungi oleh wisatawan manca Negara karena keindahannya.Sebagai warga Negara yang baik kita wajib menjaga dan melestarian kesenian yang ada di Indonesia khususnya kesenian yang ada di Bali agar tidak punah di makan oleh jaman dan oleh kemajuan kehidupan yang modern. Karena banyaknya warga asing yang datang ke pulau ini diharapkan kebudayaan asal daerah ini tidak tercampur oleh kebudayaan asing yang modern, karena kebudayaan Bali merupakan kebudayaan dari leluhur yang harus di jaga dan di rawat agar tidak punah.

Kebudayaan Bali sesungguhnya menjunjung tinggi nilai-nilai keseimbangan dan harmonisasi mengenai hubungan 
manusia dengan Tuhan (parhyangan), hubungan sesama manusia (pawongan), dan hubungan manusia dengan lingkungan (palemahan), yang tercermin dalam ajaran Tri Hita Karana (tiga penyebab kesejahteraan). Apabila manusia mampu menjaga hubungan yang seimbang dan harmonis dengan ketiga aspek tersebut maka kesejahteraan akan terwujud.

\section{Tradisi Madelokan Penganten}

Perkawinan merupakan salah satu peristiwa penting dalam sejarah kehidupan bagi hampir setiap orang. Perkawinan selalu diwarnai dengan rangkaian upacara dan adat istiadat yang mengandung nilai budaya luhur yang diwariskan nenek moyang (Sardjono, 1996). Perkawinan di Bali pada umumnya menganut sistem kekeluargaan patrilineal. Perkawinan dalam hukum adat bali terdiri atas 4 (empat) sistem yakni :

1. Sistem Mapadik, yakni perkawinan yang dilaksanakan dengan cara pihak calon suami meminta pihak calon istri. Sistemnya dilaksanakan dengan pihak calon suami datang kerumah untuk melamar atau meminta pihak calon istri untuk mengadakan perkawinan di rumah pihak calon suami;

2. Sistem Ngerorod, Bentuk perkawinan cinta sama cinta berjalan berdua/beserta keluarga laki secara resmi tak diketahui keluarga perempuan. Perkawinan ini dikenal dengan istilah kawin lari yang disebabkan para pihak tidak mendapatkan restu dari keluarga baik di satu pihak atau kedua belah pihak keluarga;

3. Sistem Nyentana, Bentuk perkawinan berdasarkan perubahan status sebagai purusa dari pihak wanita dan sebagai pradana dari pihak laki. Perkawinan jenis ini dilakukan pada umumnya karena dalam sebuah keluarga tidak memiliki keturunan laki-laki sehingga untuk meneruskan garis keturunannya melakukan perkawinan dengan sistem nyentana;

4. Sistem Melegandang, Bentuk perkawinan secara paksa tidak didasarkan cinta sama cinta.

Perkawinan di Bali kemudian mengalami perkembangan yakni muncul pula sebuah sistem perkawinan pada gelahang. Sistem perkawinan ini pada beberapa daerah di Bali khususnya di Desa Adat Kuta telah melaksanakan sistem perkawinan ini. Sistem perkawinan pada gelahang ini dilaksanakan pada dasarnya untuk menyelamatkan garis keturunan dari keluarga calon istri yang tidak memiliki keturunan pria serta tidak mendapatkan calon suami untuk melakukan perkawinan dengan sistem nyentana, maka untuk menyelamatkan garis keturunan tersebut dilakukan perkawinan dengan sistem pada gelahang. Konsep perkawinan sistem pada gelahang dilaksanakan menggunakan dasar 
sistem mepandik, tidak bisa mendasarkan pada sistem nyentana. Pada sistem perkawinan pada gelahang terdapat pengaturan berupa perjanjian terkait anak yang dilahirkan dalam perkawinan tersebut baik anak pertama atau kedua dan sebagainya yang akan menjadi penerus dari keluarga pihak istri.

Di dalam perkawinan adat bali banyak kita jumpai tradisi medelokan penganten yang merupakan sebuah tradisi yang ada di desa adat kuta dan mungkin ada juga di desa atau daerah lainnya di Bali. Tradisi adalah sebagian unsur dari sistem budaya masyarakat. Tradisi adalah suatu warisan berwujud budaya dari nenek moyang, yang telah menjalani waktu ratusan tahun dan tetap dituruti oleh merekamereka yang lahir belakangan. Tradisi itu diwariskan oleh nenek moyang untuk diikuti karena dianggap akan memberikan semacam pedoman hidup bagi mereka yang masih hidup. Tradisi itu dinilai sangat baik oleh mereka yang memilikinya, bahkan dianggap tidak dapat diubah atau ditinggalkan oleh mereka (Simanjuntak, 2016).

Tradisi medelokan penganten ini seperti namanya merupakan kegiatan medelokan (menengok / kondangan) ke rumah penganten baru. Kegiatan ini dilakukan oleh Sekaa Teruna atau biasa disingkat menjadi ST. ST merupakan generasi penerus dan tulang punggung untuk mewujudkan slogan "ajeg bali" yang selama ini digaungkan oleh pemerintah dan masyarakat di Bali. Tradisi medelekokan penganten ini hanyalah salah satu diantara banyak kegiatan lain yang menjadi program kerja sebuah ST. kegiatan ini umumnya dilakukan pada malam hari di hari pernikahan atau sehari setelah hari pernikahan. Ada yang menggabungkan kegiatan medelokan penganten ini dengan acara resepsi namun ada juga yang khusus dalam sebuah acara tersendiri. Tradisi medelokan penganten ini dihadiri oleh Kelihan Banjar, Kelihan (ketua) STT dan seluruh anggota STT. Seluruh hadirin baik laki-laki maupun perempuan menggunakan pakaian adat madya, sedangkan mempelai tentunya menggunakan pakaian adat yang lebih spesial.

\section{Hasil Penelitian}

Berdasarkan kuesioner yang telah disebar dan telah terisi lengkap, didapatkan data dengan respon rate sekitar 93\% (sembilan puluh tiga persen). Keseluruhan responden adalah Pengurus serta anggota sekaa teruna di Desa Adat Kuta, yang masing masing terdiri atas $50 \%$ (lima puluh persen) responden berjenis kelamin lakilaki dan 50\% (lima puluh persen) responden berjenis kelamin perempuan. Melihat dari jabatan para responden pada organisasi sekaa teruna tersebut terdiri dari $71 \%$ (tujuh puluh satu persen) responden sebagai pengurus sekaa teruna dan 29\% (dua puluh sembilan persen) responden sebagai anggota sekaa teruna. 
Berdasarkan data yang diperoleh dari kuesioner serta hasil dari wawancara yang telah dilakukan terhadap Bendesa Adat Kuta serta pengurus dan anggota sekaa teruna di Desa Adat Kuta, bahwa sekaa teruna banyak yang masih belum paham tentang arti tradisi medelokan penganten dan pelaksanaan tradisi medelokan penganten tersebut. Selain itu kita lihat eksistensi dari pada tradisi medelokan penganten di Desa Adat Kuta dalam lingkungan sekaa teruna tidak semua Sekaa Teruna melaksanakan tradisi medelokan penganten tersebut banyak faktor yang menyebabkannya seperti salah satunya kemungkinan disebabkan oleh generasi terdahulu mereka memang tidak pernah melaksanakan tradisi medelokan penganten tersebut dan mulai masuknya budaya- budaya yang sifatnya praktis padahal terdahulu tradisi medelokan penganten ini dilakukan dengan begitu sangat unik dan para Sekaa Teruna sangat berantusias dalam melaksanakan tradisi ini sampai menggunakan sara gong sebagai iring-iringan mereka dalam melaksanakan tradisi medelokan penganten.

Saat melakukan wawancara dengan sekaa teruna di Kuta mengenai tradisi medelokan penganten mereka semua berpendapat bahwa tradisi medelokan penganten ini sangat penting adanya terutama di lingkungan sekaa teruna karena dapat mempererat atau membina hubungan yang baik antara sekaa teruna dan mengajegkan tradisi bali yang sudah ada dari dulu agar tetap ada atau melekat untuk generasi selanjutnya. Terhadap pelaksanaan tradisi medelokan penganten itu sendiri di wilayah Kuta, tentunya diawali dengan adanya undangan dari sang penganten kemudia barulah ketua pemuda menindak lanjuti undangan tersebut dengan member taukan undangan tersebut kepada pengurus dan seluruh anggota Sekaa Teruna barulah mereka mempersiapakan segala sesuatu untuk dibawa ke acara pernikahan tersebut. Ada sekaa teruna yang melihat cendra mata yang dibawa berdasarkan keaktifan dari pada sekaa teruna tersbeut selama masih menjadi Sekaa Teruna. Misalkan saja untuk sekaa teruna yang memang aktif akan diberiakan sesuatu yang memang ketua pemuda rasakan memang seimbang atau pas dengan selama ini keaktifannya, sedangkan untuk yang kurang aktif juga sebaliknya begitu, akan tetapi terdapat juga Sekaa Teruna yang memberi inovasi baru dalam tradisi medelokan penganten misalkan saja ketua pemuda memberi sebuah sertifikat sebagai tanda ucapan terima kasih untuk kinerja selama ini dalam lingkungan sekaan teruna banjar tersebut.

Terdapat juga tradisi medelokan penganten yang mana apabila acara penganten tersebut dilakukan masih di lingkungan kuta maka para pemuda biasanya h-3 akan membantu dari pada persiapan acara tersebut, tetapi jika acara penganten tersebut 
dilakukan di kampung halamannya biasanya sekaa teruna datang hanya sebagai undangan saja. Tradisi medelokan penganten di wilayah Kuta khusunya untuk yang perempuan atau pemudi karena sifatnya dia diambil dan keluar dari sekaa teruna biasanya para sekaa teruna datang saat dia mepamit atau pergi meninggalkan rumahnya menuju rumah calon suaminya, disana pemudi tersebut juga di beriakan cendra mata sebagai ucapan terima kasih untuk pengabdiannya di sekaa teruna tersebut.

Kedatangan sekaa teruna ke rumah penganten dalam menjalankan tradisi medelokan penganten memiliki waktu khusus biasanya datang pukul 10.00 malam, dimana awalnya cara tentunya pembukaan dari ketua pemuda lalu dilanjutkan dengan pelaksanaan tradisi medelokan penganten tersebut misalnya dengan adanya sesi Tanya jawab antara penganten dengan sekaa teruna. Pertanyaan mereka juga sifatnya santai atau hanya pertanyaan-pertanyaan yang menimbulakan tawaan dan terakhir baru penyerahan cendra mata dan lain-lain. Dalam wawancara tak lupa juga Sekaa teruna menjelaskan bahwa tak banyak upaya yang dapat dilakukan dalam menjaga tradisi medelokan penganten tetapi ada beberapa upaya yang sudah dilakukan seperti meminta para tetua atau orang yang dianggap sudah ada saat di bentuknya sekaa teruna itu untuk menjelaskan atau memberi informasi kepada sekaa teruna tentang tradisi medelokan penganten.

Dalam menjalan upaya-upaya tersebut pastinya sekaa teruna juga memiliki kendala yaitu tentunya karena faktor kesibukan dengan pekerjaanya yang membuat sekaa teruna tersebut tidak ada waktu untuk mencari informasi lebih lanjut tentang tradisi medelokan penganten dan akibat masuknya pengaruh moderennisasi yang dimana lebih mudah pelaksanaanya jadi menyebabkan tradisi medelokan penganten menjadi semakin mulai tidak eksis atau tidak ada lagi.

Hasil penelitian kami juga menemukan permasalahan yang paling kompleks dihadapi oleh pemuda dalam organisasi sekaa teruna di Desa Adat Kuta adalah permasalahan kurangnya pemahaman tentang bagaimana sebenarnya pelaksanaan dari pada tradisi medelokan penganten itu sendiri. Oleh karena itu peran pemuda sangatlah penting sebagai pilar dalam menjaga dan melestarikan tradisi-tradisi yang terdahulu yang memang sangat bermanfaat dalam sebuah organisasi sekaa teruna untuk menjaga hubungan antar sesama anggota sekaa teruna. Permasalahan selanjutnya yakni adanya beberapa organisasi sekaa teruna yang tidak melaksanakan tradisi medelokan penganten dan ada organisasi sekaa teruna yang baru melaksanakan tradisi medelokan pada kepengurusan sekaa teruna yang saat ini.

Permasalahan yang dihadapi yakni kurangnya ada upaya 
preventif untuk melindungi tradisi medelokan penganten sehingga guna mencegah terjadinya kemerosotan dalam tradisi medelokan penganten perlu dibuatkan aturan berupa perarem yang khusus ditujukan kepada organisasi sekaa teruna. Berdasarkan data yang diperoleh, adapun pula draft produk yang dapat dihasilkan yakni berupa draft jurnal, draft bahan ajar serta draft perarem.

Sebagai warga Negara yang baik kita wajib menjaga dan melestarian kesenian yang ada di Indonesia khususnya kesenian yang ada di Bali agar tidak punah di makan oleh jaman dan oleh kemajuan kehidupan yang modern. Karena banyaknya warga asing yang datang ke pulau ini diharapkan kebudayaan asal daerah ini tidak tercampur oleh kebudayaan asing yang modern, karena kebudayaan Bali merupakan kebudayaan dari leluhur yang harus di jaga dan di rawat agar tidak punah.

Kebudayaan

Bali

sesungguhnya menjunjung tinggi nilai-nilai keseimbangan dan harmonisasi mengenai hubungan manusia dengan Tuhan (parhyangan), hubungan sesama manusia (pawongan), dan hubungan manusia dengan lingkungan (palemahan), yang tercermin dalam ajaran Tri Hita Karana (tiga penyebab kesejahteraan). Apabila manusia mampu menjaga hubungan yang seimbang dan harmonis dengan ketiga aspek tersebut maka kesejahteraan akan terwujud.
Tradisi medelokan penganten merupakan salah satu tradisi penting dalam sejarah kehidupan sekaa teruna. Tradisi adalah sebagian unsur dari sistem budaya masyarakat. Tradisi adalah suatu warisan berwujud budaya dari nenek moyang, yang telah menjalani waktu ratusan tahun dan tetap dituruti oleh merekamereka yang lahir belakangan. Sekaa teruna merupakan generasi penerus dan tulang punggung untuk mewujudkan slogan "ajeg bali" yang selama ini digaungkan oleh pemerintah dan masyarakat di Bali. Tradisi medelekokan penganten ini hanyalah salah satu diantara banyak kegiatan lain yang menjadi program kerja sebuah ST.

Semoga tradisi ini tetap ada dan terus terjaga. Karena banyak sekali nilai positif yang bisa diambil dalam tradisi medelokan penganten ini. Pertama tentu saja dalam menjaga kekompakan dan persatuan di kalangan generasi muda, meningkatkan solidaritas dan kepedulian terhadap sesama dan lingkungan.

Melalui kegiatan medelokan penganten ini generasi muda juga bisa banyak belajar tentang organisasi, belajar berbicara di depan umum dan ikut melestarikan budaya dan bahasa Bali. Dan masih banyak lagi hal-hal positif lainnya. Selain oleh para generasi muda di internal Sekaa Teruna masing-masing, para orangtua selaku warga adat di Banjar juga wajib terus membimbing dan memberi perhatian kepada generasi mudanya. 
Tradisi medelokan penganten merupakan tradisi yang penting untuk dijaga atau dilestarikan sehingga tradisi ini tidak pudar. Untuk menjaga tradisi medelokan penganten ini perlu peran organisasi sekaa teruna. Peran organisasi sekaa teruna dalam menjaga tradisi medelokan penganten perlu mendapatkan penguatan dalam hukum adat bali sehingga peran sekaa teruna dapat terkordinir secara jelas dalam menjaga tradisi medelokan. Pengaturan peran sekaa teruna dalam menjaga tradisi medelokan penganten dalam hukum adat bali dapat dibentuk dengan menggunakan awig-awig ataupun pararem yang didasarkan pada kesepakatan paruman.

\section{Kesimpulan}

Perkembangan pariwisata Bali memiliki dampak pada budaya Bali terutama budaya Bali pada daerah pariwisata seperti daerah Desa Adat Kuta. Berdasarkan hasil penelitian yang dilakukan pada beberapa organisasi Sekaa Teruna pada Desa Adat Kuta Pakraman, beberapa organisasi sekaa teruna yang ada di Desa Adat Kuta masih melakukan tradisi medelokan penganten, bahkan ada pula organisasi sekaa teruna yang baru mulai untuk melaksanakan kembali tradisi medelokan penganten. Perkembangan pariwisata serta perkembangan kehidupan masyarakat di Desa Adat Kuta mengakibatkan terjadinya pergeseran pelaksanaan tradisi medelokan penganten, bahkan ada pula beberapa organisasi sekaa teruna di desa adat kuta yang tidak melaksanakan tradisi medelokan penganten ini. Pelaksanaan tradisi medelokan penganten ini sangat penting menurut sekaa teruna, namun ada kendala-kendala yang dihadapi seperti kurangnya pemahaman pemuda terkait tradisi medelokan penganten baik dari segi makna dan pelaksanaan. Untuk melindungi tradisi medelokan penganten maka perlu penguatan pada organisasi sekaa teruna terutama dilakukan penguatan dengan pembentukan peraturan adat seperti perarem yang dibentuk oleh paruman di Desa Adat Kuta

\section{Saran}

Berdasarkan pada hasil penelitian diatas maka kami selaku peneliti mengajukan saran diantaranya, perlu adanya usulan upaya untuk menjaga budaya Bali pada Desa Adat Kuta serta aturan yang tegas dan konsisten dari Desa Adat Kuta untuk melindungi tradisi medelokan penganten pada Desa Adat Kuta sebagai sentral pariwisata dimana peraturan ini sebagai upaya preventif dalam menjaga budaya Bali agar tidak pudar.

\section{Daftar Pustaka}

\section{Buku}

Departeman Pendidikan Indonesia, 2008, Kamus Besar Bahasa Indonesia Edisi Keempat, PT Gramedia Pusaka Utama, Jakarta.

Marmien, Y Sardjono, 1996. Rias Pengantin Gaya Yogyakarta 
Dengan Segala Upacaranya. Kanisius, Yogyakarta.

Bungaran Antonius Simanjuntak, 2016, Tradisi, Agama, dan Akseptasi Modernisasi pada Masyarakat Pedesaan Jawa, Yayasan Pustaka Obor Indonesia, Jakarta.

\section{Jurnal}

Ardyanti, Putu Vebby Diah, dan David Hizkia Tobing, 2017, Hubungan Konsep Diri Dengan Konformitas Pada Remaja Laki-Laki Yang Mengkonsumsi Minuman Keras (Arak) Di Gianyar, Bali, Jurnal Psikologi Udayana, Volume 4, Nomor 1.

Dewi, Desak Putu Nitya, Anantawikrama Tungga Atmadja, dan Nyoman Trisna Herawati, 2017, Peran Sekaa Teruna dalam Mensosialisasikan Nilai-Nilai Akuntabilitas Berbasis Kearifan Lokal Tri Hita Karana, (Studi Kasus pada Sekaa Teruna Taruna Jaya Desa Pakraman Bangkang Baktiseraga Kecamatan Buleleng Kabupaten Buleleng Provinsi Bali Tahun 2016), JIMAT (Jurnal Ilmiah Mahasiswa Akuntansi S1), Volume 7 Nomor 1.

Dwijendra, Ngakan Ketut Acwin, 2003, Perumahan dan Permukiman Tradisional Bali, Jurnal Permukiman "Natah", Volume 1 Nomor 1.

Faisal Riza Muhammad, Hamid Djamhur , Gammahendra Fianda , 2014, Pengaruh Struktur Organisasi terhadap
Efektivitas Organisasi (Studi Pada Persepsi Pegawai Tetap Kantor Perwakilan Bank Indonesia Kediri), Jurnal Administrasi Bisnis (JAB)| Vol. 7 No. 2 Januari.

Juniarta, I Made, 2013, Dampak Perkawinan di Bawah Umur Ditinjau dari Hukum Adat Bali di Desa Kamasan, Kecamatan Klungkung, Kabupaten Klungkung, Jurnal Pendidikan Pkn, Volume 1 Nomor 2.

Satries, Wahyu Isdhardino, 2009, Peran Serta Pemuda dalam Pembangunan Masyarakat, Jurnal Madani, Edisi I.

Suastra, I Made, 2009, Bahasa Bali Sebagai Simbol Identitas Manusia Bali, Vol.16, No.30.

Widyanto, Aloysius Bram, 2010, Pemuda dalam Perubahan Sosial, Jurnal Historia Vitae, Volume 24 Nomor 2.

\section{Internet}

Sutama, I Made, 2015, Sekaa Teruna-Teruni Sebagai Pilar Mendukung Penegakan Hukum, http://www.kompasiana.co $\mathrm{m} /$ peradah/sekaa-terunateruni-sebagai-pilarmendukung-penegakanhukum_552006ec8133113d7 19de30a, (Diakses pada 16 Agustus 2017). 
